\title{
Mechanical behavior of three-hinge precast arch culvert in construction process through model experiment
}

\author{
Yasuo Sawamura $^{\text {i) }}$, Hiroyuki Ishihara ${ }^{\text {ii) }}$, Kiyoshi Kishida ${ }^{\text {iii) }}$ and Makoto Kimura ${ }^{\text {iv) }}$ \\ i) Assistant Professor, Department of Civil and Earth Resources Engineering, Kyoto University, Kyoto 615-8540, Japan. \\ ii) Hokkaido Branch, Kajima Corporation, Sapporo 060-0002, Japan. \\ iii) Associate Professor, Department of Urban Management, Kyoto University, Kyoto 615-8540, Japan. \\ iv) Professor, Department of Civil and Earth Resources Engineering, Kyoto University, Kyoto 615-8540, Japan.
}

\begin{abstract}
In recent years, the construction of precast arch culverts, which include hinges in the main body, has been increasing. Precast arch culverts have hinge function, and thus, the evaluations of the mechanical behavior in construction process and the dynamic interaction between the soil and the culvert has become an important issue. The authors conducted $1 / 5$ scale shaking table test to clarify the seismic behavior of a three-hinge precast arch culvert. Furthermore, the inner space displacement and the earth pressure of the culvert were measured at each construction stage. In this study, the relationship between the deformation of the culvert and the earth pressure acting on the culvert during construction process is discussed. From the results, it has been confirmed that the horizontal earth pressure acting on the culvert is larger than the earth pressure at rest because of the passive earth pressure when the banking height is higher than the crown.
\end{abstract}

Keywords: precast arch culvert, construction process, coefficient of earth pressure, inner space displacement

\section{INTRODUCTION}

The three-hinge precast arch culvert is a new type of culvert to save on labor at construction sites, to shorten work periods and to heighten quality control. The culvert consists of two segmental precast units and three hinge points in the body. The culvert harnesses subgrade reactions positively, by permitting deflection, and becomes a mechanically stable structure. Therefore, compared with other forms of culverts, like the box culvert which supports external forces by the rigidity of the member, the thickness of the members of this three-hinge precast arch culvert is small and construction of a large section with a high overburden is possible. With regard to the earthquake resistance of the three-hinge precast arch culvert, some experiments and numerical analyses (Byrne et al. 1996; Toyota and Takagai 1999; Toyota and Itoh 2000; Wood and Jenkins 2000) have been carried out, and earthquake-proof verification has been performed. However, the mechanical behavior of the culvert in the construction process has not often been reported.

In this study, $1 / 5$ scale shaking table test was conducted with a strong earthquake response simulator to clarify the seismic behavior of a three-hinge precast arch culvert. Furthermore, the inner space displacement and the earth pressure acting on the culvert were measured in each step of the construction process. The mechanical behavior during the construction process will be discussed here.

\section{STRUCTURE AND DESIGN}

The three-hinge precast arch culvert consists of two arch members and three hinges in the body. Fig. 1 shows the structure of this culvert. The shape of the culvert is determined to minimize the tensile forces in the arch shape, thus creating an axially loaded structure. The hinge points are at the crown and both feet of the arch. The two arch members are set to incline toward each other to form the crown hinge, and the crown beam is cast in situ to support the arches against longitudinal loads. On the other hand, at each foot hinge, the arch member is supported by an independent concrete strip foundation or a concrete slab. The foundation size is dependent upon the soil conditions, the size of the structure and the height of the backfill above the arch. The arch members are placed in simple keyways with a joint filler which appends the hinge function at each foot. The width of the arches ranges from about $5 \mathrm{~m}$ to $20 \mathrm{~m}$, while the height of the arches ranges from about $30 \%$ to $70 \%$ of the width. A detailed explanation of the design of the culvert has been given in a previous study (Hutchinson, 2004).

Fig. 2 shows the modification mode presumed in the design of a three-hinge precast arch culvert. In the 


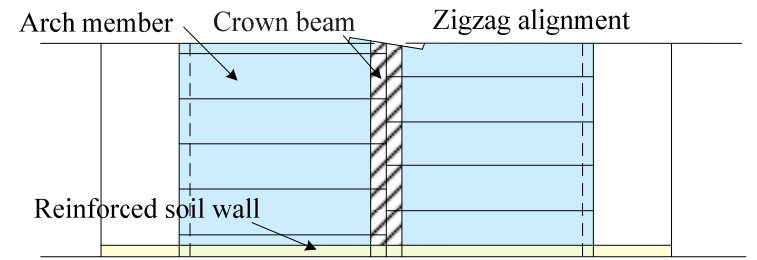

(a) Planar shape

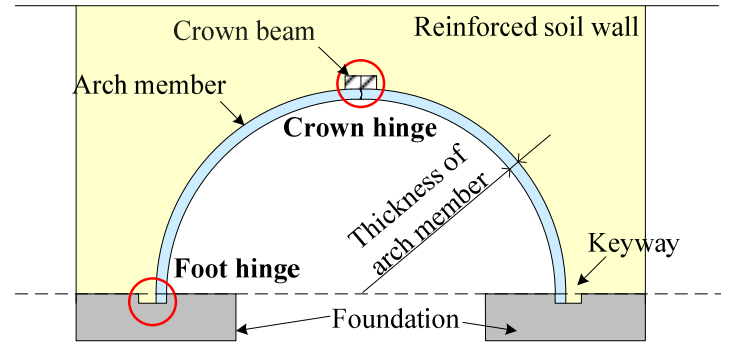

(b) Front face shape

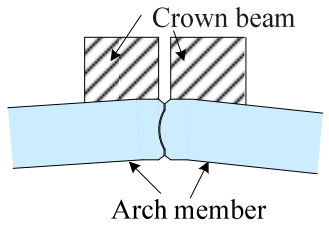

(c) Crown hinge

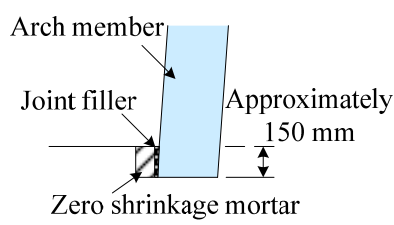

(d) Foot hinge
Fig. 1. Structure of three-hinge precast arch culvert.

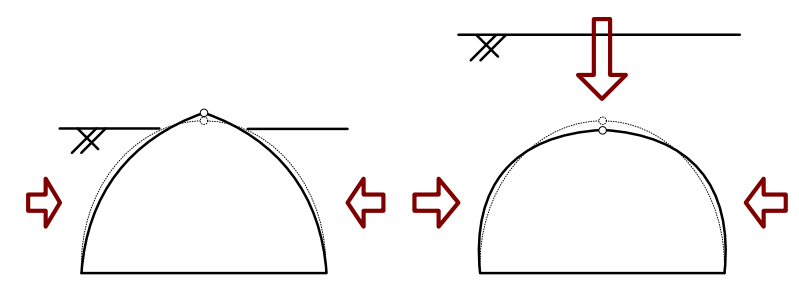

Fig. 2. Modification mode presumed in design.

present design, it is thought that when the banking height is lower than the crown of the culvert, the crown displaces upwards because the horizontal earth pressure dominates. When the banking height is higher than the crown, however, the perpendicular earth pressure of the arch culvert dominates, and it is thought that the crown is gradually depressed downwards and the whole arch deforms flatly. Therefore, it is presumed that the horizontal earth pressure acting of the culvert is larger than the earth pressure at rest. The results of the experiment are arranged based on this design presumption.

\section{MODEL EXPERIMENT}

\subsection{Experimental outline}

Fig. 3 shows the set-up of the culvert model and the arrangement of the sensors. A soil chamber, about 3.5 $\mathrm{m}$ long, $2.0 \mathrm{~m}$ deep and $1.0 \mathrm{~m}$ wide, was used for the test. The culvert model was made from reinforced concrete. Table 1 shows the material constants of the culvert model. Kagawa (1978) reported the similarity
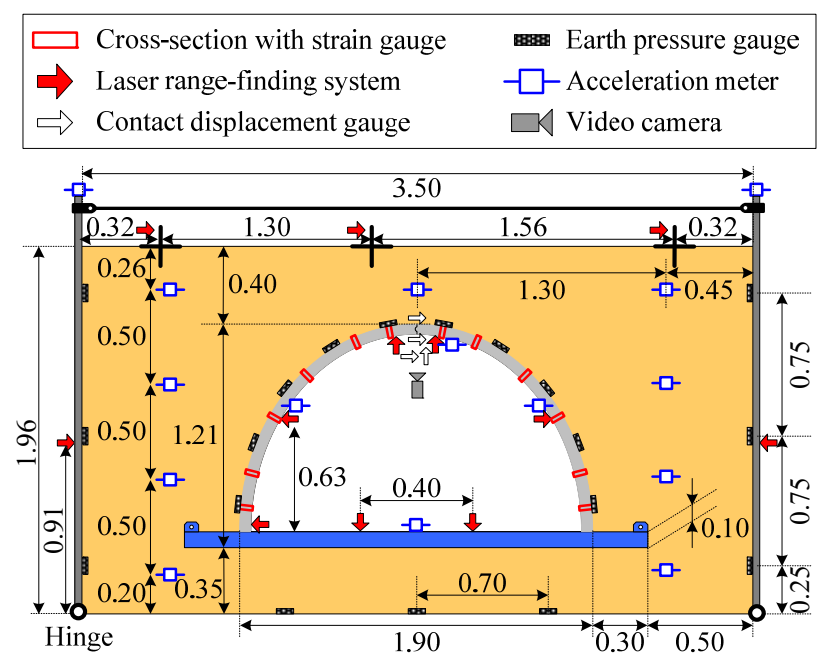

Fig. 3. Set-up of culvert model and arrangement of sensors.

Table 1. Material constants of culvert model.

\begin{tabular}{lll}
\hline Property & & Culvert \\
\hline \multirow{3}{*}{ Concrete } & Compressive strength $f_{c}\left[\mathrm{~N} / \mathrm{mm}^{2}\right]$ & 47.4 \\
\cline { 2 - 3 } & Young's modulus $E_{c}\left[\mathrm{kN} / \mathrm{mm}^{2}\right]$ & 32.4 \\
\cline { 2 - 3 } Reinforcing bar & Poisson ratio $v_{c}$ & 0.18 \\
\cline { 2 - 3 } & Yield strength $f_{y}\left[\mathrm{~N} / \mathrm{mm}^{2}\right]$ & 547.5 \\
\cline { 2 - 3 } & Young's modulus $E_{s}\left[\mathrm{kN} / \mathrm{mm}^{2}\right]$ & 190.2 \\
\cline { 2 - 3 } & Yield strain $\varepsilon_{y}[\mu]$ & 3000 \\
\hline
\end{tabular}

rule for model tests in the $1 \mathrm{G}$ gravitational field. If the similarity rule is applied, it is necessary to reduce the elastic coefficient of the culvert according to the model scale. However, it is difficult to control the elastic coefficient of concrete. Therefore, the $1 / 5$ scale culvert model, whose material parameters for concrete and the reinforcing bar are not reduced, was used. Figs. 4 and 5 show a drawing of the bar arrangement and the structure of the experimental model, respectively.

Both the foundation ground and the filling were made from Edosaki sand. Fig. 6 shows the grain size accumulation curve, and Table 2 shows the material properties of Edosaki sand. The degree of compaction of Edosaki sand was set to $92 \%$, which is the construction standard for backfill soil in a precast arch culvert. The sand was compacted with the prescribed water content $(w=20.0 \%)$ in 39 layers for every 50 $\mathrm{mm}$. In order to investigate the mechanical behavior during the construction process, the inner space displacement and the earth pressure acting on the culvert were measured at each step of the construction process.

\subsection{Experimental results}

Fig. 7 shows the transition of the inner space displacement. From the figure, it can be seen that the inner space displacement changes discontinuously when the banking height is $1.61 \mathrm{~m}$. This is because the construction process continued to the following day at this point, and the culvert followed the ground 


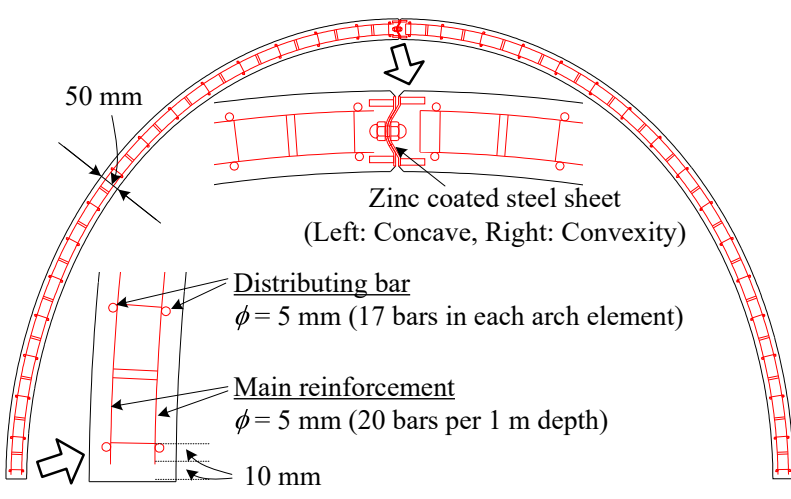

Fig. 4. Bar arrangement drawing.

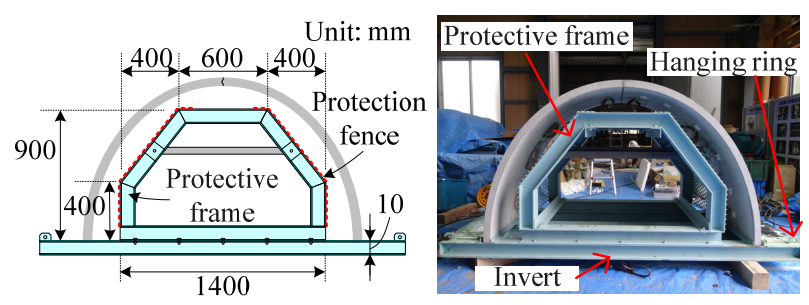

(a) Overall view

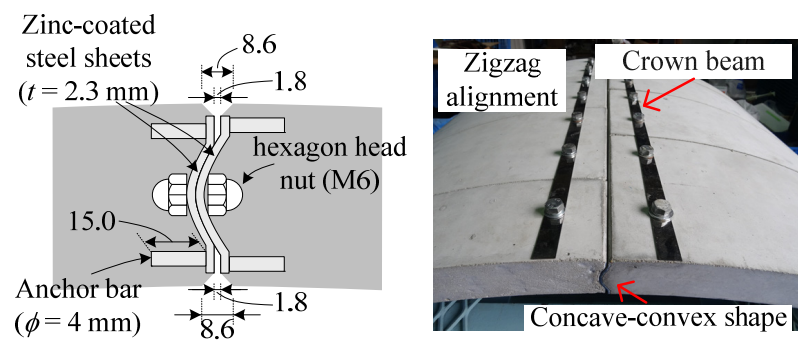

(b) Crown hinge

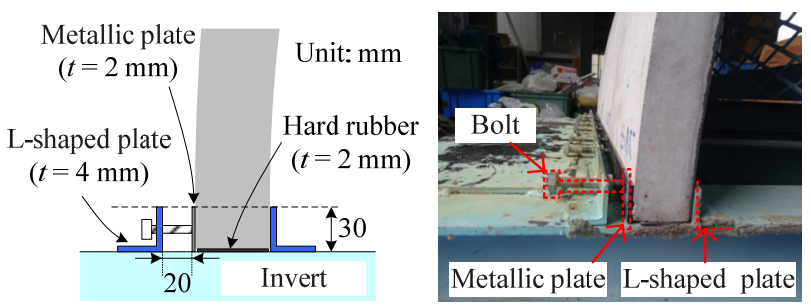

(c) Foot hinge

Fig. 5. Structure of experimental model.

consolidation. When the banking height was lower than the crown of the culvert, the displacements of the crown and both shoulders were small and the behavior assumed in the design was not observed. This is because the experimental model used in this study did not reduce the elastic coefficient of the concrete or the reinforcing bar based on the experimental scale. Thus, the rigidity of the culvert model is relatively large and the displacement of the culvert hardly develops when the banking height is low and the stress acting on the culvert is small. On the other hand, when the banking height is higher than the crown, the crown is displaced inside and both shoulders are displaced outside; such a mode is the same as that assumed in the design.

Fig. 8 shows the transition of the rotation angle of

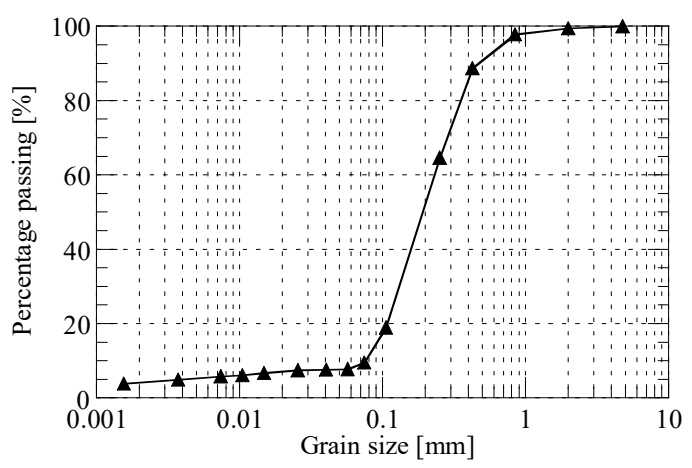

Fig. 6. Grain size accumulation curve of Edosaki sand.

Table 1. Properties of Edosaki sand.

\begin{tabular}{ll}
\hline Property & Edosaki sand \\
\hline Specific gravity of soil particle $G_{s}$ & 2.73 \\
\hline Particle size distribution $D_{50}[\mathrm{~mm}]$ & 0.18 \\
\hline Internal friction angle $\phi[\mathrm{Deg}]$ & 38.3 \\
\hline Cohesion $c[\mathrm{kPa}]$ & 14.0 \\
\hline Optimum moisture content $w_{\text {opt }}[\%]$ & 20.8 \\
\hline Maximum dry density $\rho_{\text {dmax }}\left[\mathrm{g} / \mathrm{cm}^{3}\right]$ & 1.64 \\
\hline
\end{tabular}

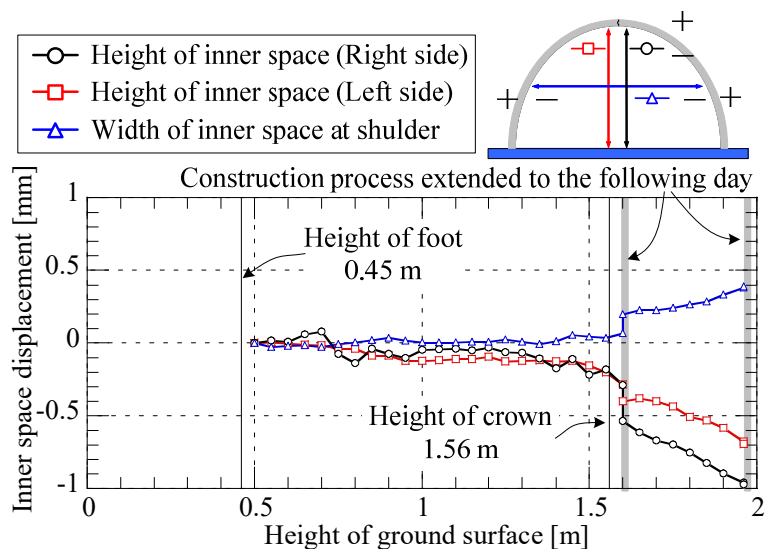

Fig. 7. Transition of inner space displacement.

the crown hinge. The crown hinge is displaced to the inner space when the banking height is lower than the crown and it is displaced to the outer space when the banking height is higher than the crown. This behavior indicates a similar tendency to that assumed in the design.

Fig. 9 shows the transition of the coefficient of earth pressure calculated from the earth pressure acting on the right-hand side arch member. Although coefficient of earth pressure $\mathrm{K}$ becomes one or more under the influence of compaction, it gradually converges to a steady value. The coefficient of earth pressure at the foot is smaller than others because the displacement of the foot is so small that the horizontal earth pressure at the point is similar to the earth pressure at rest. On the other hand, the horizontal earth pressures acting on the upper parts are larger than the earth pressure at rest because the culvert deformed flatly, and thus, these 


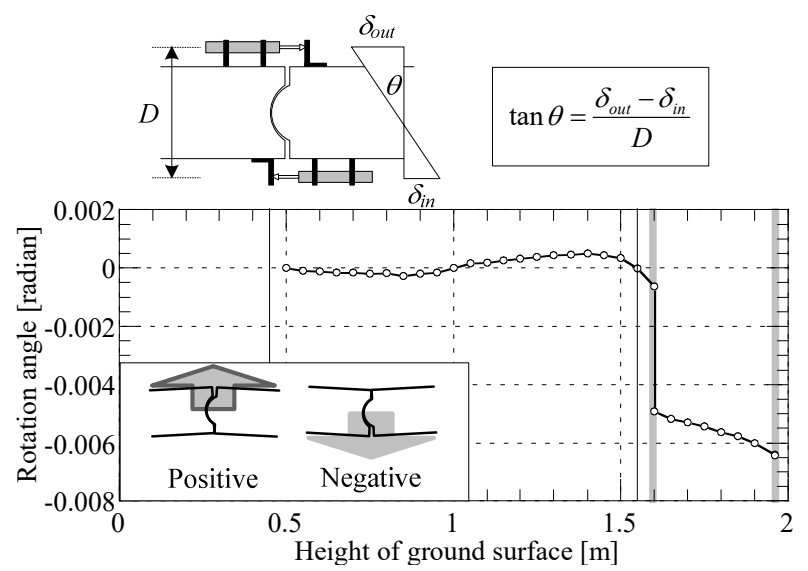

Fig. 8. Transition of rotation angle at crown hinge.

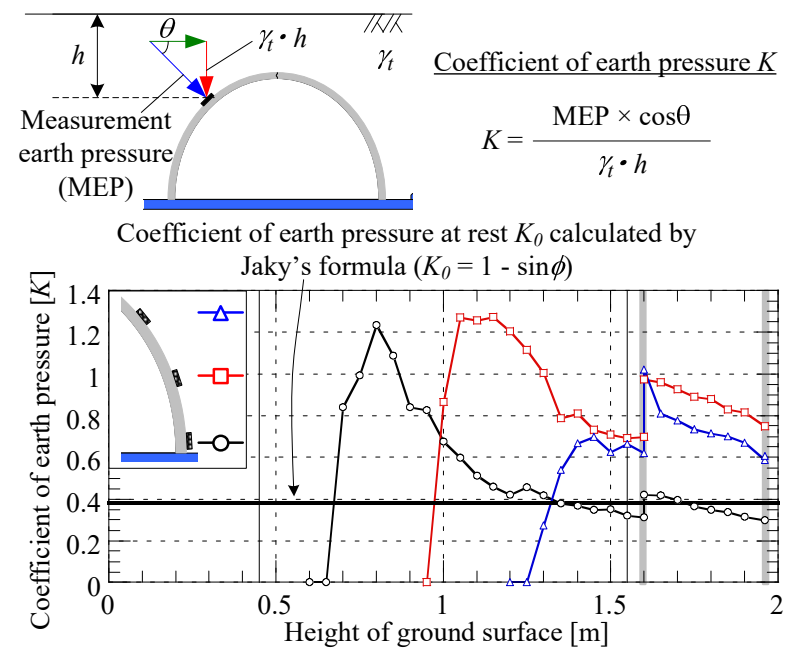

Fig. 9. Transition of coefficient of earth pressure.

parts come to be under passive earth pressure conditions.

Fig. 10 shows the distribution of earth pressure acting on the culvert in each construction stage. An equal amount of earth pressure acts on both sides of the arches; this indicates that the model ground was made appropriately. At the end of construction, the earth pressures around the shoulder parts were large because both shoulder parts were under passive earth pressure conditions.

Based on the preceding results, it was found that the coefficient of earth pressure increased according to the banking height, although the deformation of the culvert differed slightly from that of the design.

\section{CONCLUSIONS}

In this study, 1/5 scale model experiment was conducted for the three-hinge precast arch culvert to analyze the mechanical behavior of the culvert in the construction process. From this study, following conclusions can be draw:

1) The arch members are displaced according to the banking height in a similar way to that assumed in

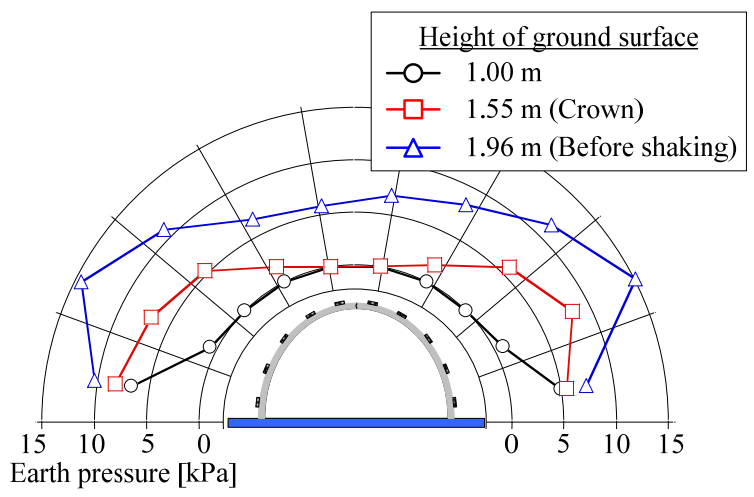

Fig. 10. Distribution of earth pressure acting on arch member.

the present design. In addition, the arch members deformed flatly and came to be under passive earth pressure conditions when the banking height was higher than the crown.

2) When the banking height is higher than the crown, the horizontal earth pressure acting on the culvert is larger than the earth pressure at rest because of the passive earth pressure.

\section{ACKNOWLEDGEMENTS}

This research was supported by the National Institute for Land and Infrastructure Management, MLIT, Japan (grant for the research and development of technologies for improving the quality of road policies, no. 24-4, 2012-2015).

\section{REFERENCES}

1) Byrne, P. M., Anderson, D. L., and Jitno, H. (1996). Seismic analysis of large buried culvert structures. Transportation Research Record 1541, Transportation Research Board, Washington, DC, pp. 133-139.

2) Hutchinson, D. (2004). Application and Design of Segmental Precast Arches. Geotechnical Engineering for Transportation Projects: pp. 452-459. (doi:10.1061/40744(154)30)

3) Kagawa, T. 1978. On the similitude in model vibration tests of earth-structures, Proc. of Japan Society of Civil Engineers, No. 275, pp. 69-77. (in Japanese)

4) Toyota, H. and Takagai, M. (1999). Dynamic Behavior of 3-hinge Arch in Terre Armee Foundation, Journal of Geotechnical Engineering, No. 624/III-47, pp. 255-266, 1999. (in Japanese)

5) Toyota, H. and Itoh, T. (2000). Effects of Shaking Conditions and Material Properties on Dynamic Behavior of Terre Armee Foundation and 3-Hinge Arch, Proc. of Japan Society of Civil Engineers, No. 666/III-53, pp. 279-289. (in Japanese)

6) Wood, J. H., and Jenkins, D. A. (2000). Seismic analysis of buried arch structures. Proc. of 12th World Conf. on Earthquake Engineering, New Zealand Society for Earthquake Engineering, Wellington, New Zealand. 